\title{
The Students' Readiness to Engage with Mobile Learning Apps
}

\author{
Camilleri $^{1}$, M.A. and Camilleri ${ }^{2}$ A.C.
}

This is a pre-publication version.

How to Cite: Camilleri, M.A. \& Camilleri, A.C. (2019). The Students' Readiness to Engage with Mobile Learning Apps. Interactive Technology and Smart Education. DOI: 10.1108/ITSE-06-2019-0027

Purpose: A relevant literature review suggests that today's children are increasingly immersing themselves in ubiquitous technologies, including interactive media and digital games. Therefore, this research investigates the primary school students' intrinsic and extrinsic motivations toward learning via gameplay through their mobile devices, at home, and at school.

Design: This study was carried out among primary school students in a small European state. It used valid and reliable measures, that comprised the technology acceptance model's key constructs. However, the empirical investigation also explored the students' perceived enjoyment and social influences, as plausible antecedents for their behavioral intention to engage with the educational applications (apps).

Findings: The findings reported that there were strong correlations between the students' perceived usefulness of the mobile technologies and their behavioral intention to use them for their learning. The results also indicated that there was no significant relationship between the perceived ease of use and the children's enjoyment in engaging with the educational apps that were used at school.

Originality: To the best of our knowledge, there is no other study in academia that has explored the children's technology acceptance, normative pressures and their intrinsic motivations to use mobile learning technologies in the context of primary education. Therefore, this contribution opens future research directions, as this study can be replicated in other contexts.

Keywords: mobile learning; technology acceptance model, perceived ease of use, perceived usefulness, perceived enjoyment, normative pressures, behavioral intention, educational apps.

\footnotetext{
${ }^{1}$ Department of Corporate Communication, Faculty of Media and Knowledge Sciences, University of Malta, Msida, MSD2080, MALTA. Email: $\underline{\text { mark.a.camilleri@um.edu.mt }}$

${ }^{2}$ Institute of Community Services, Malta College of Arts, Sciences and Technology, Korradino Road, Paola, PLA9032, MALTA.

Email: adriana.camilleri@mcast.edu.mt
} 


\section{Introduction}

The use of ubiquitous technologies, including; mobile devices and interactive media have inevitably changed how students think and process information (Ge \& Ifenthaler, 2018; Sánchez \& Isaías, 2018; 2017). Very often they are utilizing digital learning games in education as these technologies provide an immersive, yet enjoyable experience to their users (Bourgonjon, Valcke, Soetaert \& Schellens, 2010; Hwang \& Wu, 2012). These educational technologies are increasingly satisfying the basic requirements of the schools' educational programs as they are blended in their learning environments (Carvalho, Bellotti, Berta, De Gloria, Sedano, Hauge, Hu \& Rauterberg, 2015; Connolly, Boyle, MacArthur, Hainey \& Boyle, 2012). Several studies reported that the educational apps can enhance students' motivation to learn (Burguillo, 2010; Dickey, 2011). Therefore, the gameplay via educational apps is supporting the children's cognitive development during their learning journey (Huang, Huang \& Tschopp, 2010; Harris, Mishra \& Koehler, 2009). Consequently, the digital learning technologies hold great potential to improve the students' knowledge and skills in an informal manner (Wouters, Van Nimwegen, Van Oostendorp \& Van Der Spek, 2013; Camilleri \& Camilleri, 2019a, 2017).

There are a number of theoretical frameworks that have been used by academia to explore the students' engagement with such educational technologies in different contexts, including; the Technology Acceptance Model (Davis, 1989; Davis, Bagozzi \& Warshaw, 1989); the Theory of Planned Behavior (Ajzen, 1991), the Self Determination Theory (Lee, Cheung \& Chen, 2005; Chen \& Jang, 2010); and the Uses and Gratifications Model (Dunne, Lawlor \& Rowley, 2010; Li, Liu, Xu, Heikkilä \& Van Der Heijden, 2015), among others. Hence, this study has adapted the valid and reliable measures to explore the primary school students' perceptions and motivations toward educational apps. This contribution sheds light on the grade three students' use, ease of use and enjoyment of mobile learning technologies. It also investigates whether these young individuals are influenced by their peers, parents, and/or teachers to engage in the schools' educational apps. This contribution addresses a gap in academic knowledge as it 
examines the rationale behind the students' intentions to use mobile learning technologies, at home and at school.

\section{Literature Review}

\subsection{Mobile Learning Applications}

The hand-held mobile devices such as smart phones and tablets allow individuals, including students, to access and review online (educational) content from virtually anywhere. The mobile applications (apps) can provide instant access to the schools' learning resources (Camilleri \& Camilleri, 2019b; Sánchez \& Isaías, 2017; Cheon, Lee, Crooks \& Song, 2012). Therefore, they are increasingly being utilized in the context of primary education to improve the student experience. Relevant theoretical underpinnings reported that more primary level students are utilising mobile learning technologies to engage with their instructors (Rodríguez, Riaza \& Gómez, 2017; Sánchez \& Isaías, 2018). Notwithstanding, it is much easier for the younger pupils to mobile apps to read eBooks, as hard-copy textbooks need to be carried in their bags.

Arguably, the proliferation of portable technologies like tablets are lighter and less bulky than laptop computers. Hence, primary school students can easily use mobile technologies anywhere, beyond the traditional classroom environment (Rodríguez et al., 2017). Currently, there is a wide variety of educational apps that are readily available on a wide array of mobile devices (Chee, Yahaya, Ibrahim \& Hasan, 2017; Domingo \& Garganté, 2016). Such interactive technologies can improve the delivery of quality education as teachers provide direct feedback to their students, in real time. Some of the mobile apps can even engage primary school students in immersive learning experiences (Camilleri \& Camilleri, 2019c; Isaias, Reis, Coutinho \& Lencastre, 2017). 
On the other hand, other academic literature posited that some students may not want to engage in mobile learning. Very often, commentators implied that the mobile technologies have their own limitations (Cheon et al., 2012; Wang, Wu \& Wang, 2009). A few practitioners contended that mobile devices had small screens with low resolutions. Alternatively, some argued about their slow connection speeds, or pointed out that they lacked standardization features (Sánchez \& Isaías, 2017; Camilleri \& Camilleri, 2017). As a matter of fact, Android, Apple and Microsoft Windows have different operating systems. As a result, learning apps may have to be customized to be compatible with such systems.

Moreover, individuals, including primary school students may hold different attitudes towards the use of mobile devices. There may be students who may be motivated to engage with mobile technologies (Sánchez \& Isaias, 2018; Ciampa, 2014) as they use these devices to play games, watch videos, or to chat with their friends, online (Wang et al., 2009). In this case, the primary school students may use their mobile devices for hedonic reasons, rather than to engage in mobile learning activities. Such usage of the mobile technologies can possibly result in undesired educational outcomes.

Nevertheless, those primary level students who already own or have instant access to a mobile device may easily become habitual users of this technology; as they use it for different purposes. However, there is still limited research in academia that explores these students' readiness to engage in mobile learning at home, and at school.

\subsection{The Formulation of Hypotheses}

A relevant literature review suggests that many researchers have often validated measures that were drawn from the Theory of Planned Behavior, the Technology Acceptance Model (TAM) and/or from the Unified Theory of Acceptance and Use of Technology, among others. TAM has received empirical support in 
academia for being robust in predicting the users' technology adoption in various contexts, and with a variety of innovations (Davis, 1989; Davis et al., 1989). TAM indicated that the individuals' behavioral intention to use technology would be determined by their attitude, which would, in turn, be conditioned by the usefulness and the ease of use of the information systems (Davis et al., 1989). The perceived usefulness and the perceived ease of use are the key determinants of the individuals' attitude toward computer usage behaviors (Davis et al., 1989).

\section{- Perceived Ease of Use of Technology}

In 1989, Fred Davis defined perceived ease of use (PEoU) as the degree to which a person believes that using a particular system would be free of effort (Teo, Beng Lee, Sing Chai \& Wong, 2009). He explored the extent to which a person thinks that technology is user-friendly and easy to use. Alternatively, individuals may find that the technology is difficult to understand and use. If they think that the technology is complex, tedious and/or time-consuming; it is very likely that they will reject the technology. As a result, they won't be productive and efficient if they feel uneasy, apprehensive, or fearful of using computers (Camilleri \& Camilleri, 2017b). Therefore, both computer anxiety or PEoU can have an impact on the adoption of innovative technologies. For this reason, the PEoU has a significant direct effect on the perceived usefulness (PU) of the technology (Davis, 1989; Davis et al., 1989).

\section{- Perceived Usefulness of Technology}

The "perceived usefulness" (PU) of the technology is the degree to which a person believes that using a particular system would enhance his or her job performance (Davis, 1989). The PU has to do with the degree to which a person believes that the technology will help him or her to perform a certain task in an efficient and productive manner. Hence, the PU construct is concerned with the expected overall impact of technology on the individual's job performance (in terms of process and outcome). The PU has a direct effect on the individuals' intention to use, and actual usage of the technology (Davis et al., 1989). 
Moreover, the PEoU positively influences the PU (Davis, 1989). In simple words, if the technology is easy to use the individuals can benefit from it. Therefore, PEoU is a precursor of the individuals' technology acceptance. Conversely, technology may help individuals to achieve a goal or increase their desired performance. Therefore, the individuals would perceive the usefulness of the technology. As a result, they may be willing to use the technology.

The behavioral intention is formed as a result of the individuals' conscious decision-making processes (Ajzen, 1991), as there are strong relationships between the PU of the technology and the behavior intention to use it, and between behavioral intention and actual usage of the technology (Teo et al., 2009). However, the PU and PEoU are worse predictors of actual usage than behavioral intention, with PEoU being significantly worse than behavioral intention (Park, 2009). TAM does not include subjective or objective measures of technology usage. Perhaps, TAM should be supplemented and extended by using the subjective norm and image (Venkatesh, Morris, Davis \& Davis, 2003). It can include variables that are related to both human and social change processes (Venkatesh, Thong \& Xu, 2012). Other authors remarked that TAM should explain the adoption of technology by introducing external variables that could possibly determine the chain of influence from the independent variables to the dependent variables, as it is the case for TPB's behavioral intention (Venkatesh et al., 2003; 2012].

\section{- Perceived Enjoyment from the Usage of Technology}

The users' technology acceptance is influenced by the extrinsic motivations, including the perceived usefulness; as they may be aware that the technology will improve their performance. However, there may also be intrinsic motivations that can have an effect on the users' engagement with the technology (Lee et al., 2005). The intrinsic motivation involves the performance of an activity for no apparent reinforcement other than the process of performing the activity per se (Chen \& Jang, 2010; Ryan \& Deci, 2000). The self-determination theory (SDT)'s motivation framework has often been used to explore the use of technology in different contexts, including in the realms of education (Lee et al., 2005). In a nutshell, SDT 
suggests that individuals engage in activities that are satisfying, enjoyable or challenging, in order to satisfy their psychological needs (Chen \& Jang, 2010). The users' intrinsic motivations are derived from emotional feelings that may include either happiness or frustration (Dunne et al., 2010). The intrinsically motivated individuals would probably engage in activities that they perceive as interesting and pleasant (Lee et al., 2005). Many persons seek gratifications when they use media and technology (Dunne et al., 2010; Li et al, 2015). Their non-utilitarian gratifications, including; enjoyment, fun-seeking, and entertainment can influence their behavioral intention to use technology (Lee et al., 2005).

\section{- Normative Pressures}

Individuals may be influenced by the normative beliefs and the social pressures to perform or not to perform certain behaviors (Venkatesh et al., 2003; 2012). The normative pressure (or the subjective norm) is defined as "the person's perception that most people who are important to him/her think that s/he should or should not perform the behavior in question (Ajzen, 1991). For instance, the students may experience social pressures from their educators, classmates, parents, et cetera to use technology in class (Cheon et al., 2012). Thus, the students' social influences can affect their usage and acceptance of educational technologies (Venkatesh et al., 2003; 2012).

\section{- Behavioral Intention and Actual Usage of Technology}

The behavioral intention is determined by the individual's personal attitude toward the behavior and by the normative pressures that are experienced by individuals (Ajzen, 1991; Venkatesh et al., 2012). The behavioral intention to use technological innovations is an important factor that determines whether users will actually utilize the technologies (Venkatesh et al., 2003). Many studies have explored the relationship between behavioral intention and actual usage of technology in different contexts (Park, 2009; Venkatesh et al., 2003, 2012; Chang, Hajiyev \& Su, 2017; Park, Nam \& Cha, 2012). 
Essentially, this study builds on the TAM and has integrated the constructs of "perceived enjoyment" and "normative pressures" in its empirical investigation. This research explores the following hypotheses:

H1: The students' perceived ease of use of mobile learning games is positively related to their perceived enjoyment in playing them.

H2: The students' perceived usefulness of mobile learning games is positively related to their perceived enjoyment through gameplay.

H3: The students' perceived ease of use of mobile learning games is an antecedent of perceived usefulness, as reported in the Technology Acceptance Model.

H4: The perceived usefulness, ease of use and enjoyment, as well as the normative pressures from parents, teachers and other students are the antecedents for the students' engagement with the mobile learning games.

\section{Methodology}

\subsection{Research Design}

This exploratory study uses valid and reliable measures, that comprised eight items from TAM's perceived usefulness and perceived ease of use of the educational apps. It includes four items that measured the users' perceived enjoyment; three items that explored the users' social influences, as well as three items that investigated the student's behavioral intention to use the technology at home and at school.

\subsection{Participants}

A pilot study was carried out among 148 grade-3 students in a small EU state. The participants were between 8-9 years of age. There were 90 males (61\%) and 58 female participants (39\%) in this study. 


\subsection{Measures}

The questions were presented in a child-friendly layout as the questionnaire was designed to be as clear, simple and straightforward as possible. The questionnaire was interesting and easy to read. Therefore, the questions were brief and concise. The researchers avoided the use of difficult, ambiguous language, jargon and technical terms. Hence, the questionnaire did not formulate questions with more than one meaning that could have been subject to different interpretations. The questionnaire's statements were adapted to the young students to ensure that they will be easily understood by them. The scales were adapted to the students to ensure that they will be easily understood by them (Camilleri \& Camilleri, 2019c). To elicit responses, the questionnaire featured three-point, child-friendly, Likert scales that included colorful, smiley faces that enticed the students' participation in the survey. The structure of the questionnaire appeared in the same format in order to facilitate its completion.

\subsection{Procedure}

The class teachers were expected to provide support to all students to better understand the survey's questions, yet they were committed not to influence their responses in any way. The students were divided into groups of three or four, and they were supported during the data gathering process. The questionnaire was filled in by the students in 10-15 minutes time (under the supervision of the researcher).

\section{Results}

\subsection{Descriptive Statistics}

Table 1 shows the descriptive statistics on the perceived usefulness, ease of use and enjoyment constructs. It also indicates whether the respondents were experiencing normative pressures from their peers, teachers, and parents to play educational apps, at home and at school. The scores suggest that the children had high 
levels of technological acceptance as well as high levels of enjoyment in their gameplay, at home and school; as the means were all above 2 .

The findings indicated that the children played more games at home than they did at school (Wilcoxon, $\mathrm{z}$ $=-3.729, \mathrm{p}<0.05$ ) and they enjoyed the games more at home than at school (Wilcoxon, $\mathrm{z}=2.681, \mathrm{p}<$ 0.05). Students perceived the games they play at school were easy to play than the educational games at home (Wilcoxon, $\mathrm{z}=-3.187, \mathrm{p}=0.001$ ). They considered the use of the educational games at school more useful (Wilcoxon, $\mathrm{z}=-3.214, \mathrm{p}=0.001$ ) relevant (Wilcoxon, $\mathrm{z}=-3.187, \mathrm{p}=0.008$ ) and learnt more from them (Wilcoxon, $\mathrm{z}=-2.493, \mathrm{p}=0.013$ ) than playing educational games at home. There was no difference between the home and school games' in terms of fun (Wilcoxon, $\mathrm{z}=-0.378, \mathrm{p}=0.705$ ), excitement (Wilcoxon, $\mathrm{z}=-0.504, \mathrm{p}=0.614$ ), holding attention (Wilcoxon, $\mathrm{z}=-0.338, \mathrm{p}=0.735$ ), generation of interest (Wilcoxon, $\mathrm{z}=-0.632, \mathrm{p}=0.527$ ), enjoyable (Wilcoxon, $\mathrm{z}=-2.681, \mathrm{p}=0.1$ ) and commitment to use (Wilcoxon, $\mathrm{z}=-0.462, \mathrm{p}=0.181$ ). In addition, there was no difference in terms of the teacher's influence (Wilcoxon, $\mathrm{z}=-1.807, \mathrm{p}=0.71$ ), or the parents' expectations (Wilcoxon, $\mathrm{z}=-0.158, \mathrm{p}=0.29$ ) between playing educational games at home and at school. The young students indicated that they were willing to play (Wilcoxon, $\mathrm{z}=-1.944, \mathrm{p}=0.041$ ) with the educational games at home, rather than at school. The results suggested that they will probably continue using them (Wilcoxon, $\mathrm{z}=-1.818, \mathrm{p}=$ 0.022 ) as they enjoyed playing them and also find them useful and easy to use. 
Table 1. Playing Educational Games at Home and at School

\begin{tabular}{|c|c|c|c|c|c|c|}
\hline \multirow[t]{2}{*}{ Construct } & \multicolumn{2}{|c|}{ Home } & \multicolumn{2}{|c|}{ School } & \multirow{2}{*}{$\begin{array}{c}\text { Wilcoxon } \\
\mathrm{Z}\end{array}$} & \multirow{2}{*}{$\begin{array}{c}\text { Sig. } \\
p\end{array}$} \\
\hline & $\mathbf{M}$ & SD & $\mathbf{M}$ & SD & & \\
\hline \multicolumn{7}{|c|}{ Perceived Enjoyment } \\
\hline Play & 3.03 & 1.37 & 2.15 & 1.13 & -3.72 & 0.00 \\
\hline Fun & 2.90 & 0.39 & 2.91 & 0.38 & -0.37 & 0.71 \\
\hline Exciting & 2.80 & 0.51 & 2.83 & 0.49 & -0.50 & 0.61 \\
\hline Interesting & 2.75 & 0.57 & 2.80 & 0.48 & -0.63 & 0.52 \\
\hline Enjoyable & 2.88 & 0.41 & 2.88 & 0.41 & -2.68 & 0.00 \\
\hline \multicolumn{7}{|c|}{ Perceived Ease of Use } \\
\hline Easiness of gameplay & 2.46 & 0.72 & 2.81 & 0.50 & -3.18 & 0.00 \\
\hline $\begin{array}{l}\text { Understand-able } \\
\text { games }\end{array}$ & 2.31 & 0.82 & 2.56 & 1.10 & -1.05 & 0.05 \\
\hline Ease of use & 2.30 & 1.10 & 2.11 & 0.90 & -1.11 & 0.07 \\
\hline Skilled & 2.15 & 1.00 & 2.08 & 0.84 & -0.95 & 0.09 \\
\hline \multicolumn{7}{|c|}{ Perceived Usefulness } \\
\hline Holds Attention & 2.65 & 0.63 & 2.61 & 0.61 & -0.33 & 0.73 \\
\hline Learn & 2.58 & 0.64 & 2.81 & 0.46 & -2.49 & 0.01 \\
\hline Useful & 2.36 & 0.82 & 2.78 & 0.52 & -3.21 & 0.00 \\
\hline Relevant & 2.41 & 0.95 & 2.81 & 0.48 & -2.64 & 0.00 \\
\hline \multicolumn{7}{|c|}{ Normative Pressures } \\
\hline Teachers & 2.31 & 0.87 & 2.50 & 0.70 & -1.80 & 0.07 \\
\hline Parents & 2.75 & 0.62 & 2.83 & 0.45 & -0.15 & 0.29 \\
\hline Peers & 2.21 & 1.30 & 2.40 & 1.28 & -1.57 & 0.15 \\
\hline \multicolumn{7}{|c|}{ Behavioral Intention } \\
\hline Willingness to use & 2.46 & 1.10 & 2.35 & 0.47 & -1.94 & 0.04 \\
\hline Probable usage & 2.50 & 0.84 & 2.44 & 0.59 & -1.81 & 0.02 \\
\hline Committed to use & 2.28 & 0.72 & 2.31 & 1.57 & -0.46 & 0.18 \\
\hline
\end{tabular}

\subsection{Data Reduction}

The Kaiser Meyer Olkin (KMO) measure of sampling adequacy was acceptable at 0.901. Bartlett's test of sphericity also revealed sufficient correlation in the dataset to run a principal component analysis (PCA) since $\mathrm{p}<0.001$. An exploratory factor analysis (EFA) has been chosen to obtain a factor solution from a much larger dataset. A pro-max rotation method was used to examine the component correlation matrix. The results suggested that the correlation between the components was important as it was more than 0.2, therefore the factor scores were retained. The values less than 0.4 were suppressed. EFA indicated that there were many variables that shared close similarities as there were highly significant correlations. There were patterns within the data that were expressed by highlighting relevant similarities (and differences) in 
each component. In the process, the data has been compressed as it was reduced to 5 dimensions. Table 2 illustrates the amount of variance in the original variables (with their respective initial eigenvalues) for each component.

With respect to the scale's reliability, all constructs were analyzed for internal consistency by using Cronbach's alpha. The composite reliability's coefficients were well above the minimum acceptance value of 0.7 . The extracted factors accounted for more than $80 \%$ variance. The factor components were labelled following a cross-examination of the variables with the higher loadings. Typically, the variables with the highest correlation scores had mostly contributed towards the make-up of the respective component. The underlying scope of combining the variables by using component analysis was to reduce the data and make it more adaptable for regression analysis.

Table 2. Total Variance Explained

\begin{tabular}{|c|c|c|c|c|c|c|c|}
\hline \multirow[t]{2}{*}{ Factor } & \multicolumn{3}{|c|}{ Initial Eigenvalues } & \multicolumn{3}{|c|}{$\begin{array}{l}\text { Extr. Sum of Sqr } \\
\text { Loadings }\end{array}$} & \multirow{2}{*}{$\begin{array}{c}\text { Rot. Sum of } \\
\text { Sqr. } \\
\text { Loadings }\end{array}$} \\
\hline & Eig. & $\begin{array}{l}\text { \% of } \\
\text { Var. }\end{array}$ & Cum. & Eig. & $\begin{array}{l}\text { \% of } \\
\text { Var. }\end{array}$ & Cum. & \\
\hline 1. Behavioral Intention & 10.9 & 59.403 & 59.403 & 10.7 & 58.338 & 58.388 & 9.064 \\
\hline $\begin{array}{l}\text { 2. Perceived } \\
\text { Usefulness }\end{array}$ & 1.326 & 7.221 & 66.624 & 1.14 & 6.809 & 65.197 & 7.384 \\
\hline 3. Normative Pressures & 1.015 & 5.04 & 71.664 & 0.72 & 4.234 & 69.431 & 5.289 \\
\hline $\begin{array}{l}\text { 4. Perceived } \\
\text { Enjoyment }\end{array}$ & 0.895 & 4.881 & 76.545 & 0.68 & 3.448 & 72.879 & 6.348 \\
\hline $\begin{array}{l}\text { 5. Perceived Ease of } \\
\text { Use }\end{array}$ & 0.813 & 3.908 & 80.453 & 0.61 & 2.658 & 75.537 & 6.217 \\
\hline
\end{tabular}

Extraction Method: Principal Axis Factoring

\subsection{Testing of the Hypotheses}

The four hypothesized relationships were investigated by using the multivariate regression analysis. A stepwise procedure was chosen to select the most significant, predictive variables in the regression equations. Therefore, the p-value was set at less than the 0.05 benchmark. This also resulted in adequate 
F-ratios and the corresponding t-statistics; implying that only the significant amounts of variation in regression were accounted for. More importantly, in the stepwise procedure the insignificant variables were excluded without appreciably increasing the residual sum of squares. The regression models produced the regression coefficients that represented the strength and the significance of the relationships.

H1: There were no significant relationships between the students' perceived ease of use of the educational apps and the perceived enjoyment from their gameplay, both at home and at school. The results for the first hypothesis were inconclusive.

$\mathrm{H} 2$ : The students enjoyed playing the educational games as they held perceived them as useful at home (where adj. $\mathrm{r} 2=0.406, \mathrm{t}=1.323$ ), and at school (where adj. $\mathrm{r} 2=0.28, \mathrm{t}=3.874$ ). These results were highly significant, as $\mathrm{p}<0.01$.

H3: The students' perceived ease of use of the educational games was positively and significantly related to the perceived usefulness of the game, where the adj. $\mathrm{r} 2=0.368, \mathrm{t}=2.865$, and $\mathrm{p}<0.05$.

H4: The perceived use and enjoyment were positive and significant antecedents for the students' behavioral intention to engage with the educational games. There was an adj. $\mathrm{r} 2=0.264$ and $\mathrm{t}=0.842$ between PU and BIU, and an adj. $\mathrm{r} 2$ of 0.411 , where $\mathrm{t}=1.105$ between PE and BIU. In both cases, $\mathrm{p}<$ 0.05. However, the findings suggested that perceived ease of use and the normative pressures were not significant antecedents for the students' behavioral intention to play the educational game.

\section{Conclusions}

This contribution has explored the primary school's grade three students' intrinsic and extrinsic motivations toward the use of mobile learning apps. It relied on the technology acceptance model to investigate the students' perceived usefulness and ease of use of the schools' educational games (Dickey, 
2011; Huang et al., 2010; (Lee et al., 2005). Moreover, the researchers have also included measuring items that explored the students' perceived enjoyment (Davis, 1989; Davis et al., 1989; Camilleri \& Camilleri, 2017b) as they investigated whether they experienced normative pressures to play the educational apps (Ajzen, 1991; Venkatesh et al., 2003, 2012). The findings from the Wilcoxon test reported that the students played the school games at home, more than they did at school. They indicated that educational apps were easy to play. This study reported that the students recognized that the school's games were useful and relevant as they were learning from them. Moreover, they indicated that the school's educational games held their attention since they found them enjoyable and fun.

The vast majority of the children played mobile learning games, both at home and at school. The findings in this study are consistent with the argument that digital natives are increasingly immersing themselves in digital technologies (Bourgonjon et al., 2010), including educational games (Camilleri \& Camilleri, 2019; Ge \& Ifenthaler, 2018; Carvalho et al., 2015, Wouters et al., 2013). However, the results have shown that there was no significant relationship between the perceived ease of the gameplay and the children's enjoyment in them. Furthermore, the stepwise regression analysis revealed that there was no significant relationship between the normative expectations and the children's engagement with the educational apps; although it was evident (from the descriptive statistics) that the parents were encouraging their children to play the games at home and at school.

This research relied on previously tried and tested measures that were drawn from the educational technology literature in order to explore the hypothesized relationships. There is a common tendency in academic literature to treat the validity and reliability of quantitative measures from highly cited empirical papers as given. In this case, the survey items in this study were designed and adapted for the primary school children who were in grade 3, in a small European state. Future studies may use different sampling frames, research designs and methodologies to explore this topic. 
To the best of our knowledge, there is no other empirical study that has validated the technology acceptance model within a primary school setting. Further work is needed to replicate the findings of this research in a similar context.

\section{Acknowledgements}

We thank the department of education, the school's principal and her members of staff who have provided their invaluable support during the data gathering process.

\section{References}

Ajzen, I. (1991), "The theory of planned behavior", Organization Behaviour and Human Decision Processes, Vol. 50, No. 2, pp. 179-211.

Bourgonjon, J., Valcke, M., Soetaert, R., and Schellens, T. (2010), “Students' perceptions about the use of educational games in the classroom", Computers \& Education, Vol. 54, No. 4, pp. 1145-1156.

Burguillo, J.C. (2010), "Using game theory and competition-based learning to stimulate student motivation and performance", Computers \& Education, Vol. 55, No. 2, pp. 566-575.

Camilleri, M.A. and Camilleri, A. (2017a), "The Technology Acceptance of Mobile Applications in Education”, In Sánchez, I.A. \& Isaias, P. (Eds) 13th International Conference on Mobile Learning (Budapest, 11th April). Proceedings, pp 41-48. International Association for Development of the Information Society.

Camilleri, M.A., and Camilleri, A.C. (2017b), "Digital learning resources and ubiquitous technologies in education”, Technology, Knowledge and Learning, Vol. 22, No. 1, pp. 65-82.

Camilleri, M. A., and Camilleri, A. (2019a), "Student Centred Learning Through Serious Games", 13th Annual International Technology, Education and Development Conference. Valencia, Spain (March, 2019). International Academy of Technology, Education and Development (IATED).

Camilleri, A.C., and Camilleri, M.A. (2019b), "Mobile Learning via Educational Apps: An Interpretative Study”. In Shun-Wing N.G., Fun, T.S. \& Shi, Y. (Eds.) 5th International Conference on Education and Training Technologies (ICETT 2019). Seoul, South Korea (May, 2019). International Economics Development and Research Center (IEDRC).

Camilleri, A.C., and Camilleri, M.A. (2019c), “The Students Intrinsic and Extrinsic Motivations to Engage with Digital Learning Games", In Shun-Wing N.G., Fun, T.S. \& Shi, Y. (Eds.) 5th International Conference on Education and Training Technologies (ICETT 2019). Seoul, South Korea (May, 2019). International Economics Development and Research Center (IEDRC). 
Carvalho, M.B., Bellotti, F., Berta, R., De Gloria, A., Sedano, C.I., Hauge, H.B., Hu, J., and Rauterberg, M. (2015), "An activity theory-based model for serious games analysis and conceptual design", Computers \& Education, Vol. 87, pp.166-181.

Chang, C.T., Hajiyev, J., and Su, C.R. (2017), "Examining the students' behavioral intention to use elearning in Azerbaijan? The general extended technology acceptance model for e-learning approach", Computers \& Education, Vol. 111, pp. 128-143.

Chee, K. N., Yahaya, N., Ibrahim, N. H., and Hasan, M. N. (2017). Review of mobile learning trends 2010-2015: A meta-analysis. Journal of Educational Technology \& Society, 20(2), 113-126.

Chen, K. C. and Jang, S. J. (2010), "Motivation in online learning: Testing a model of self-determination theory", Computers in Human Behavior, Vol. 26, No. 4, pp. 741-752.

Cheon, J., Lee, S., Crooks, S. M. and Song, J. (2012), “An investigation of mobile learning readiness in higher education based on the theory of planned behavior", Computers \& Education, Vol. 59, No. 3, pp. 1054-1064.

Ciampa, K. (2014), "Learning in a mobile age: an investigation of student motivation", Journal of Computer Assisted Learning, Vol. 30, No. 1, pp. 82-96.

Connolly, T.M., Boyle, E.A., MacArthur, E. Hainey, T., and Boyle, J.M. (2012), “A systematic literature review of empirical evidence on computer games and serious games", Computers \& Education, Vol. 59, No. 2, pp. 661-686.

Davis, F.D. (1989), "Perceived usefulness, perceived ease of use, and user acceptance of information technology”, MIS Quarterly, Vol. 13, No. 3, pp. 319-340.

Davis, F.D., Bagozzi, R.P., and Warshaw, P.R. (1989), "User acceptance of computer technology: a comparison of two theoretical models", Management Science, Vol. 35, No. 8, pp. 982-1003.

Dickey, M.D. (2011), "Murder on Grimm Isle: The impact of game narrative design in an educational game-based learning environment", British Journal of Education Technology, Vol. 42, No. 3, pp. 456469.

Domingo, M. G. and Garganté, A. B. (2016). Exploring the use of educational technology in primary education: Teachers' perception of mobile technology learning impacts and applications' use in the classroom. Computers in Human Behavior, Vol. 56, pp. 21-28.

Dunne, Á., Lawlor, M. A., and Rowley, J. (2010), "Young people's use of online social networking sites-a uses and gratifications perspective", Journal of Research in International Marketing,. Vol. 4, No. 1, pp. 46-58.

Ge, X., and Ifenthaler, D. (2018), "Designing engaging educational games and assessing engagement in game-based learning", In Gamification in Education: Breakthroughs in Research and Practice, IGI Global, Hershey, USA, pp. 1-19.

Harris, J. Mishra, P., and Koehler, M. (2009), “Teachers' technological pedagogical content knowledge and learning activity types: Curriculum-based technology integration reframed", Journal of Research on Technology in Education, Vol. 41, No. 4, pp. 393-416.

Huang, W.H., Huang, W.Y., and Tschopp, J. (2010), "Sustaining iterative game playing processes in DGBL: The relationship between motivational processing and outcome processing", Computers \& Education, Vol. 55, No. 2, pp. 789-97. 
Hwang, G.J., and Wu, P.H. (2012), “Advancements and trends in digital game-based learning research: a review of publications in selected journals from 2001 to 2010", British. Journal of Education Technology, Vol. 43, No. 1, pp. E6-E10.

Isaias, P., Reis, F., Coutinho, C. and Lencastre, J. A. (2017), "Empathic technologies for distance/mobile learning: An empirical research based on the unified theory of acceptance and use of technology (UTAUT)", Interactive Technology and Smart Education, Vol. 14, No. 2, pp. 159-180.

Lee, M. K., Cheung, C. M., and Chen, Z. (2005), "Acceptance of Internet-based learning medium: the role of extrinsic and intrinsic motivation”, Information \& Management,. Vol. 42, No. 8, pp. 1095-1104.

Li, H., Liu, Y., Xu, X., Heikkilä, J., and Van Der Heijden, H. (2015), "Modeling hedonic is continuance through the uses and gratifications theory: An empirical study in online games", Computers in Human Behavior, Vol. 48, pp. 261-272.

Park, S.Y. (2009), “An analysis of the technology acceptance model in understanding university students' behavioral intention to use e-learning”, Education. Technology \& Society, Vol. 12, No. 3, pp. $150-162$.

Park, S. Y., Nam, M. W., and Cha, S. B. (2012), "University students' behavioral intention to use mobile learning: Evaluating the technology acceptance model”, British Journal of Education Technology, Vol. 43, No. 4, pp. 592-605.

Rodríguez, A. I., Riaza, B. G., \& Gómez, M. C. S. (2017), "Collaborative learning and mobile devices: An educational experience in Primary Education”, Computers in Human Behavior, Vol. 72, pp. 664677.

Ryan, R. M., and Deci, E. L. (2000), "Intrinsic and extrinsic motivations: Classic definitions and new directions", Contemporary Education Psychology, Vol. 25, No. 1, pp. 54-67.

Sánchez, I. A., \& Isaías, P. (2017), "Proceedings of the International Association for Development of the Information Society (IADIS)", International Conference on Mobile Learning (13th, Budapest, Hungary, April 10-12, 2017). International Association for Development of the Information Society.

Sánchez, I. A., \& Isaias, P. (2018), "Proceedings of the International Association for Development of the Information Society (IADIS)", International Conference on Mobile Learning (14th, Lisbon, Portugal, April 14-16, 2018). International Association for Development of the Information Society.

Teo, T., Beng Lee, C., Sing Chai, C., and Wong, S.L. (2009), "Assessing the intention to use technology among pre-service teachers in Singapore and Malaysia: A multigroup invariance analysis of the Technology Acceptance Model (TAM)”, Computers \& Education, Vol. 53, No. 3, pp. 1000-1009.

Venkatesh, V., Morris, M.G., Davis, G.B. and Davis, F.D. (2003), "User acceptance of information technology: Toward a unified view”, MIS Quarterly, Vol. 27, No. 3, pp. 425-478.

Venkatesh, V., Thong, Y.T.L., and Xu, X. (2012), "Consumer acceptance and use of information technology: extending the unified theory of acceptance and use of technology", MIS Quarterly, Vol. 36, No.1, pp. 157-178.

Wang, Y. S., Wu, M. C., \& Wang, H. Y. (2009), "Investigating the determinants and age and gender differences in the acceptance of mobile learning", British Journal of Educational technology, Vol. 40, No. 1, pp. 92-118.

Wouters, P., Van Nimwegen, C., Van Oostendorp, H., and Van Der Spek, E.D. (2013), "A meta-analysis of the cognitive and motivational effects of serious games", Journal of Education Psychology, Vol. 105, No. 2, pp. 249-266. 
